\title{
Association Between Caregivers' Knowledge and Perceptions and Whether their Children Complete Tuberculosis Preventive Treatment
}

Jhon Alex Zeladita ( $\sim$ jhonzeladita@hotmail.com )

Universidad Maria Auxiliadora https://orcid.org/0000-0002-5419-5793

Courtney M. Yuen

Harvard Medical School Department of Global Health and Social Medicine

Roberto Zegarra-Chapoñan

Universidad Nacional Mayor de San Marcos Facultad de Medicina de San Fernando

Maricela Curisinche-Rojas

Instituto Nacional de Salud

Vicente Egusquiza-Pozo

Universidad Maria Auxiliadora

Research article

Keywords: Tuberculosis, preventive therapy, isoniazid, children, adolescents, Peru

Posted Date: August 18th, 2020

DOI: https://doi.org/10.21203/rs.3.rs-51633/v1

License: (9) This work is licensed under a Creative Commons Attribution 4.0 International License.

Read Full License 


\section{Abstract}

Background: Giving preventive therapy to children living in the households of TB patients to prevent them from developing TB themselves is important for reducing morbidity and mortality in this high-risk group. Children's adherence to medications is likely dependent on their caregivers. We conducted a study to assess the association between caregivers' knowledge and perceptions around isoniazid preventive therapy (IPT) and whether their children completed IPT.

Methods: We conducted a retrospective medical record review of children who initiated IPT during 20172018 in 50 health facilities in south Lima, Peru. We administered structured surveys to caregivers of the children and about their knowledge and perceptions around IPT. To determine factors associated with IPT completion, we used a modified Poisson regression with generalized estimating equations to account for clustering by household.

Results: We included in the study 550 children, of whom $31 \%$ did not complete IPT. Independent factors associated with not completing IPT were: low caregiver knowledge about TB and IPT (adjusted risk ratio [aRR]: $1.41 ; 95 \%$ confidence interval [CI]: 1.06-1.78), low caregiver perception of the importance of IPT (aRR: 1.76; 95\% Cl: 1.30-2.39), low caregiver satisfaction with the health services (aRR: 1.57; 95\% Cl: 1.142.16), experiencing adverse events (aRR: $2.08 ; 95 \% \mathrm{Cl}: 1.51-2.87$ ), and living in a household with moderate or severe family dysfunction (aRR: $1.53 ; 95 \% \mathrm{Cl}: 1.07-2.19$ ).

Conclusions: IPT completion among children was associated with the knowledge and perceptions of their caregivers, as well as whether they experienced adverse events. To improve IPT completion among children, health care providers should prioritize education and counseling for caregivers, promote positive interpersonal relationships with them, and monitor adverse events.

\section{Background}

Globally, an estimated 1.1 million children develop tuberculosis (TB) each year (1). Upon infection with Mycobacterium tuberculosis, a person may develop TB rapidly or may enter a state of latent TB infection in which the immune system controls the infection, but which can later develop into active TB disease (2, $3)$. The risk of developing TB disease after infection is greatest in infancy $(40 \%)$, but also high in children (25\%) and adolescents (10 a 15\%) (4). Children in close contact with adults who have TB are at high risk of being infected, and if TB disease develops, they can develop fatal disseminated forms such as military TB and TB meningitis $(4,5)$. Given these considerations, the World Health Organization (WHO) recommends that household contacts receive preventive therapy as part of a strategy to reduce the risk of pediatric TB (2). The most common regimen used for preventive therapy in low- and middle-income countries is 6 months of daily isoniazid, referred to as isoniazid preventive therapy, or IPT. Globally, it is estimated that only $27 \%$ of young children ( $<5$ years old) who were household contacts of TB patients received preventive therapy in 2018 ; the number who completed this treatment was not reported to WHO (1). 
Studies identifying factors associated with IPT completion under programmatic conditions have been published from diverse settings. In South Africa, more children completed preventive therapy when treatment was supervised by health care workers or community treatment supporter, and more children completed treatment when a shorter treatment regimen was used (6). In India, IPT completion was better in rural clinics than in urban clinics (7). Studies from Brazil have found that non-completion of IPT was associated with the human development index of the patient's residence and with having contact with a TB patient who had not completed treatment (8), and with low socioeconomic status (9). In Peru, completion of IPT has been associated with receiving a tuberculin skin test, TB treatment completion of the index patient, and health facility characteristics (10).

Many of these studies have identified associations between IPT completion and demographic or clinical characteristics of the child or the index patient. However, to inform programmatic improvement, it is important to also assess factors that health care providers can modify while a person is in care. For example, providers can potentially affect patients' perceptions of the importance of treatment through education or counseling. For children, IPT is likely to depend on the caregiver, but relatively few studies have focused on caregivers' perceptions or knowledge of IPT $(11,12)$. Moreover, the association between caregivers' perceptions and knowledge and whether their children complete IPT is unclear. For example, one mixed methods study found no quantitative association between IPT completion and caregiver knowledge and perceptions, and yet found these to be important facilitators of adherence in qualitative analysis (13). This qualitative evidence that caregiver perceptions affect IPT completion is corroborated by other research (14), but quantitative evidence of an association is lacking. To address this knowledge gap, we conducted a study in Lima, Peru to assess the association between caregivers' knowledge and perceptions of IPT and whether their children completed IPT.

\section{Methods}

\section{Study design}

We conducted a cross-sectional study of children who had received IPT and their caregivers. The objective was to measure the association between the knowledge and perceptions of caregivers and whether their children completed IPT. To adjust for other factors that could affect IPT completion, we used the WHO conceptual framework for medication adherence (15).

\section{Study population}

The Directorate of the Integrated Health Networks of South Lima (Dirección de Redes Integradas de Salud [DIRIS] Lima Sur) manages 136 health facilities located in 13 districts in the south of Lima, comprising a catchment population of 1.86 million. The percentage of the population living in poverty $(17.7 \%)$ is higher than in other areas of Lima. For this study, we enrolled caregivers whose children had received IPT in 50 of the health centers that reported the highest TB caseloads in 2017, representing $80 \%$ of the total TB cases in the DIRIS Lima Sur. 
To identify caregivers for recruitment, we reviewed medical records to identify children who were age $<19$ years, contacts of TB patients, and who initiated IPT during 2017-2018. We excluded children whose address was not legible, who had moved, who had been diagnosed with TB during IPT, or who for whom IPT had been suspended by the managing physician. We then recruited the caregivers of identified eligible children during May-August 2019. The inclusion criteria for caregivers were that they were the mother, father, or family member of the child who had received IPT; that they were at least 18 years old; and that they were the person who routinely collected weekly IPT medication refills and had been in charge of managing the child's IPT in the household.

\section{Data collection}

Data were collected to enable assessment of factors for IPT completion based on the WHO framework for medication adherence (15). The outcome of the analysis was whether the child completed 24 weeks of IPT. We defined this outcome based on the report of the caregiver, but we verified the information via medical records. Our two principal predictors of interest were in the domain of factors related to knowledge, attitudes, and perceptions. Specifically, we assessed caregivers' knowledge about TB and IPT and their perception of the importance of IPT. In the domain of health system-related factors, we assessed the satisfaction that the caregiver expressed with the health care staff who managed IPT for their child. In the domain of social and economic factors, we considered the age and sex of the child; the age, sex, education level, and occupation of the caregiver; as well as family function, as measured by the Family APGAR questionnaire (16). Finally, in the domain of factors related to treatment, we considered whether the child had any adverse event during IPT.

Data were collected via a structured survey administered to caregivers in their homes. True-or-false questions assessing caregiver knowledge were formulated based on basic information stated in the Peru national TB guidelines (17). If a caregiver did not respond to one of the questions, the survey taker would repeat the question, and if the caregiver did not answer, the survey taker recorded a response of "does not know," which we considered as an incorrect answer. We defined a low level of knowledge as correctly answering $<6$ of the 8 questions about TB and IPT. To assess caregivers' perception of the importance of IPT and their satisfaction with health care staff, we treated survey responses as a Likert scale and calculated the average response over the two questions in each category. Low perceived importance of IPT importance was defined as an average score of $<2$ out of a possible 3 across the two associated questions (a score of 2 corresponding to an average response of "somewhat important"), and low satisfaction with health services was defined as an average score of $<3$ out of a possible 4 across the two associated questions (a score of 3 corresponding to an average response of "satisfied"). If a caregiver did not answer one of the questions in the category, we counted only the question that they answered. The survey also contained questions about the age, sex, and occupation of the caregiver; whether the caregiver was the index patient; and whether the child experienced any adverse events during treatment. The occurrence of adverse events was verified in the children's medical records. Finally, the survey contained the questions from the Family APGAR, and we defined moderate or severe dysfunction 
as corresponding to scores indicating low or moderate satisfaction with family function (16). The questionnaire was validated by TB experts and through a pilot test with 15 participants.

\section{Statistical analysis}

To assess factors associated with IPT completion, we calculated risk ratios (RR) with 95\% confidence intervals $(\mathrm{Cl})$ using modified Poisson regression with generalized estimating equations to account for correlation among children in the same household. In multivariable analysis, we determined a priori that we would include caregiver knowledge and caregiver perception of IPT importance, since these were our predictors of interest. We considered for inclusion other variables with a p-value of 0.15 in bivariate analysis. We limited multivariable analysis to caregivers with complete data (i.e. no unanswered survey questions). Statistical analysis was performed in SAS v9.4 (SAS Institute, Cary, NC, USA).

\section{Results}

We identified 590 children who had initiated IPT during the period of interest, and we enrolled caregivers of 550 (93\%) of these children. We excluded 39 children whose families had moved outside the jurisdiction of the health facility, 1 child who developed TB disease, and 2 children for whom IPT had been suspended. The 550 included children lived in 367 households; $35 \%$ of households had more than one child. Among the children, 311 (57\%) were male, and 358 (65\%) were under 5 years old. In total, 380 (69\%) of the children completed IPT. Adverse events were reported by caregivers and verified in medical records for $34(6 \%)$ of children.

We administered surveys to 367 caregivers, whose characteristics are described in Table 1. Among caregivers, $81 \%$ were women, $66 \%$ had achieved a maximum education level of secondary school, and $47 \%$ were themselves the TB patient to whom the child was exposed. 
Table 1

Social and demographic characteristics of enrolled caregivers $(\mathrm{N}=367)$

\begin{tabular}{|llll|}
\hline Characteristics of caregivers & $\mathbf{n}$ & $\%$ \\
\hline Age (years) & 164 & 45 \\
\hline $18-30$ & 129 & 35 \\
\hline $31-45$ & 74 & 20 \\
\hline$>45$ & & \\
\hline Sex & 69 & 19 \\
\hline Male & 298 & 81 \\
\hline Female & & \\
\hline Is the caregiver the TB patient? & 173 & 47 \\
\hline Yes & 194 & 53 \\
\hline No & & \\
\hline Highest level of education attained & & 11 \\
\hline Primary or lower & 39 & 241 & 66 \\
\hline Secondary & 87 & 24 \\
\hline Post-secondary & & & \\
\hline
\end{tabular}

\section{TB and IPT knowledge among caregivers}

With respect to knowledge of TB transmission 354 (97\%) caregivers knew that TB was transmitted through the air (Table 2). Consistently, $96 \%$ of caregivers correctly stated that TB transmission can be prevented by maintaining good ventilation, and $91 \%$ correctly stated that transmission can be prevented by avoiding being close to a person with TB who is coughing. However, many caregivers incorrectly believed that TB could be transmitted by sharing utensils (58\%) or by touching a person with TB $(19 \%)$, and $62 \%$ incorrectly believed that having TB patients use separate dishes and utensils was an appropriate TB preventive measure. The median number of questions answered correctly by caregivers was 6 (interquartile range $5-7$ ). 
Table 2

Caregiver knowledge about tuberculosis (TB) and isoniazid preventive therapy (IPT) ( $N=367)$

Caregivers who responded correctly

\section{Questions}

Knowledge about TB transmission

Can TB be transmitted through the air when a person coughs or sneezes?

Can TB can be transmitted by sharing utensils?

Can TB can be transmitted by touching a person with TB?

Knowledge about TB preventive measures

Can family members avoid getting TB by maintaining well-ventilated rooms?

Can family members avoid getting TB by maintaining physical distance from the person who has TB

Can family members avoid getting TB by not being close to the person with TB when they cough or sneeze?

Can family members avoid getting TB by keeping separate plates and utensils for the person with TB?

Knowledge about IPT

What could happen if a child does not take IPT?*

* Responses mentioning that the child could fall sick with TB were considered correct

152

297

352

252

332

137

$354 \quad 97$

42

81

96

69

91 38 $\%$

9

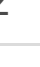


Table 3

Caregiver responses to questions about importance of isoniazid preventive therapy (IPT) and satisfaction with health services $(\mathrm{N}=367)$

\section{Caregiver responses}

$\begin{array}{lll}\text { Questions } & \mathbf{n} & \%\end{array}$

Perceptions about importance of IPT

How important did you feel it was for your child to complete IPT?

Not important or not very important 23 6

Somewhat important 148 40

Very important 195 53

No response 1 $<1$

Before starting treatment, how likely did you think it was that your child would develop TB?

Not likely or not very likely 67 18

Somewhat likely 129 35

Very likely 169 46

No response

2

1

Satisfaction with health services

How would you rate your satisfaction with the attention you received from the health facility staff?

Very unsatisfied

10

3

Unsatisfied

23

6

Satisfied

196

53

Very satisfied

136

37

No response

1

$<1$

How would you rate the friendliness and courtesy of the person who gave you the isoniazid?

Very poor 5

1

Poor

11

3

Good

169

Very good

179

49

No response

3

1

Risk factors for not completing IPT 
In bivariate analysis, non-completion of IPT was associated with low caregiver knowledge about TB and IPT (RR: 1.71, 95\% Cl: 1.29-2.77), low caregiver perception of IPT importance (RR: 2.11; 95\% Cl: 1.572.84), and low caregiver satisfaction with health services (RR: 2.00; 95\% Cl: 1.46-2.74) (Table 4). In addition, children who experienced adverse events were over twice as likely to not complete IPT (RR: 2.36; $95 \% \mathrm{Cl}: 1.75-3.17)$. Finally, IPT non-completion was associated with the caregiver not being the index patient (RR: 1.44 ; $95 \% \mathrm{Cl}: 1.05-1.91)$ and moderate or severe family dysfunction (RR: $1.78 ; 95 \% \mathrm{Cl}: 1.22-$ 2.61). 
Table 4

Bivariate and multivariable associations between caregiver characteristics and isoniazid preventive therapy (IPT) completion in child contacts

Characteristic

Bivariate analysis

Multivariable analysis

$\begin{array}{llllll}\mathrm{RR} & \begin{array}{ll}95 \% \\ \mathrm{Cl}\end{array} & \begin{array}{l}\mathrm{p}- \\ \text { value }\end{array} & \text { aRR } & \begin{array}{l}95 \% \\ \mathrm{Cl}\end{array} & \begin{array}{l}\mathrm{p}- \\ \text { value }\end{array}\end{array}$

Caregiver TB knowledge High Ref

$\begin{array}{lllllll}\text { Low } & 1.71 & \begin{array}{l}1.22- \\ 2.61\end{array} & 0.003 & 1.41 & \begin{array}{l}1.06- \\ 1.78\end{array} & 0.017\end{array}$

Caregiver perception of

IPT importance

High

Ref

Low $\quad 2.11$

$1.57-<$

$2.84 \quad 0.001$

1.76

$1.30-<$

$2.39 \quad 0.001$

Caregiver satisfaction

with health services

High

Ref

Low

2.00

$1.46-<$

2.74

0.001

1.57

1.14-

2.16

Caregiver sex

Female Ref

$\begin{array}{llll}\text { Male } \quad 1.25 & \begin{array}{l}0.89- \\ 1.74\end{array} & 0.197\end{array}$

Caregiver age (years)

\begin{tabular}{llll}
$18-30$ & Ref & & \\
\hline $31-45$ & 1.07 & $\begin{array}{l}0.75- \\
1.55\end{array}$ & 0.682 \\
& & 1.52 & \\
\hline $46+$ & 0.87 & $0.62-$ & 0.409 \\
& & 1.22 & \\
& & &
\end{tabular}

Caregiver is the TB patient

No

Ref

Yes

1.41

$1.05-$

0.025

1.22

$0.92-$

1.61

0.166

Caregiver highest

education level
More than

secondary

Secondary or below

No

Yes

Functional

Caregiver perception of

family function

Caregiver works
Ref

$\begin{array}{lll}1.25 & 0.86- & 0.233 \\ 1.82 & \end{array}$

Ref

1.32

$0.98-$
1.80

0.067

1.23

$0.93-$

1.64

0.149

Ref

$\mathrm{RR}=$ risk ratio, $\mathrm{Cl}$ = confidence interval, $\mathrm{aRR}=$ adjusted risk ratio, $\mathrm{Ref}=$ reference category 


\begin{tabular}{|c|c|c|c|c|c|c|c|}
\hline & $\begin{array}{l}\text { Moderate or severe } \\
\text { dysfunction }\end{array}$ & 1.78 & $\begin{array}{l}1.22- \\
2.61\end{array}$ & 0.003 & 1.53 & $\begin{array}{l}1.07- \\
2.19\end{array}$ & 0.018 \\
\hline \multirow[t]{2}{*}{ Child contact sex } & Female & Ref & & & & & \\
\hline & Male & 1.11 & $\begin{array}{l}0.96- \\
1.28\end{array}$ & 0.154 & & & \\
\hline \multirow[t]{3}{*}{ Child contact age (years) } & $\leq 4$ & Ref & & & & & \\
\hline & $5-9$ & 0.88 & $\begin{array}{l}0.75- \\
1.04\end{array}$ & 0.136 & 0.93 & $\begin{array}{l}0.82- \\
1.06\end{array}$ & 0.282 \\
\hline & $10-18$ & 0.97 & $\begin{array}{l}0.82- \\
1.14\end{array}$ & 0.720 & 0.99 & $\begin{array}{l}0.83- \\
1.18\end{array}$ & 0.881 \\
\hline \multirow{2}{*}{$\begin{array}{l}\text { Child experienced } \\
\text { adverse event }\end{array}$} & No & Ref & & & & & \\
\hline & Yes & 2.36 & $\begin{array}{l}1.75- \\
3.17\end{array}$ & $<.001$ & 2.08 & $\begin{array}{l}1.51- \\
2.87\end{array}$ & $\begin{array}{l}<.001 \\
0.001\end{array}$ \\
\hline
\end{tabular}

The multivariable analysis included 520 children with complete data for all variables considered (Table 4). Low caregiver knowledge about TB and IPT (adjusted risk ratio [aRR]: 1.41; 95\% Cl: 1.06-1.78), low caregiver perception of IPT importance (aRR: 1.76; 95\% Cl: 1.30-2.39), and low caregiver satisfaction with health services (aRR: $1.57 ; 95 \% \mathrm{Cl}$ : 1.14-2.16) remained independently associated with IPT noncompletion. In addition, children who experienced adverse events were still twice as likely not to complete IPT (aRR: 2.08; 95\% Cl: 1.51-2.87). Moderate or severe family dysfunction also remained independently associated with IPT non-completion (aRR: 1.53; 95\% Cl: 1.07-2.19).

\section{Discussion}

In this study, completion of IPT for child contacts of TB patients was associated with their caregivers' knowledge about TB and their perceptions of the importance of IPT. IPT completion was also associated with the occurrence of adverse events, caregivers' satisfaction with health services, and family environment. Our findings contrast with previous studies that did not find significant associations between caregivers' knowledge about IPT and their children's IPT completion $(13,18)$. However, our results are consistent with studies of adult patients, which have found that they are less likely to complete IPT if they lack knowledge about its purpose (19) or do not believe that they are at risk for TB (20). It is possible that the relationship between caregivers' knowledge and perceptions and their willingness or ability to support their children's treatment completion may vary across settings. Nevertheless, our findings suggest the importance of efforts on the part of the health system to educate, counsel, and build positive relationships with caregivers of children receiving IPT.

While we found that a large majority of caregivers were satisfied with the services they received from the health system, those who reported dissatisfaction were more likely to have children who did not complete 
IPT. Importantly, because the survey was administered after children had already stopped IPT, we cannot be sure whether dissatisfaction with the health services was a contributing cause of IPT non-completion, or whether dissatisfaction resulted from a situation that contributed to IPT non-completion (e.g. adverse events that went unattended by the health system). However, previous studies have also reported that positive support from health care providers is a facilitating factor for IPT adherence (13) and that negative relationships between caregivers and health care providers can adversely impact IPT adherence (21). Together, this evidence suggests that implementing strategies focused on fostering trusting relationships between caregivers and health care providers could encourage caregivers to return to the health facility for medication refills and inform providers about the occurrence of adverse events, and could encourage caregivers to promote IPT adherence in the home.

Few children in our study experienced adverse events, consistent with what has been observed internationally under clinical trial conditions (22) and under programmatic conditions in Peru (23). However, we found that the occurrence of adverse events was a risk factor for not completing IPT. This finding is consistent with other studies that have used interviews to identify adverse events $(24,25)$, but not with some studies that analyzed information from treatment registers $(8,26)$. This discrepancy could mean that contacts may stop taking IPT if an adverse event occurs without reporting it to the health services, or that the perception of adverse events from a patient or caregiver's point of view may not be the same as the definition applied by health care providers. Moreover, studies based on recall may be subject to bias if patients who struggled to complete treatment are more likely to recall experiencing adverse events; on the other hand, studies based on treatment registers may be subject to the opposite bias if patients who remain in care are more likely to have their adverse events recorded by the health system. Notwithstanding these limitations, the results of our study and other interview-based studies suggests that concern over adverse events may present a challenge to IPT completion, and therefore, active monitoring of adverse events is important for supporting adherence.

Our observation that family function, as measured by the Family APGAR, was associated with IPT completion suggests that the family environment influences adherence behaviors. This finding is consistent with studies from other disease areas, which have found that the family function is associated with adherence to chronic disease treatments in children (27). Family support has also been shown to be associated with adherence to treatment for TB disease in adults (28). While the mechanisms may be similar, it is unknown how exactly the family environment affects IPT completion in child contacts, and future studies could help increase understanding in this area. This knowledge is important for developing strategies to support IPT adherence in households with challenging family environments.

Our study is subject to several limitation. Because the interviews were administered retrospectively, responses could have been affected by incomplete recall or recall bias. However, were able to verify some of the information, such as IPT completion and the occurrence of adverse events, from medical records. Also, because of the timing of the survey, the knowledge and perceptions reported during the survey may not reflect the situation while the children were taking IPT, so it is difficult to interpret potential mechanisms of causality based on observed associations. Social desirability bias could have made 
caregivers reluctant to express negative opinions about the importance of IPT or satisfaction with health services. We attempted to mitigate this risk by administering the surveys in participants' homes rather than at health facilities, ensuring confidentiality of responses, and training the survey administrators to ask questions in a standardized manner. Finally, the exclusion of children whose families had moved could represent a source of bias, although these families represented a small percentage of the total.

\section{Conclusions}

In this study, we found that IPT completion in child contacts of TB patients was associated with their caregivers' knowledge about TB, perceptions of the importance of IPT, and satisfaction with health services, as well as the occurrence of adverse events and the family environment. These findings, in combination with finding from other studies in this area, suggest that health systems should prioritize education and counseling for caregivers of child contacts receiving IPT. Education and counseling could help caregivers better understand the importance of IPT for preventing TB disease and promote positive relationships between families affected by TB and the health system. Increased understanding and positive relationships could in turn support IPT adherence and the monitoring of adverse events. Ultimately, increasing the effective use of IPT will help reduce TB morbidity and mortality among children.

\section{Abbreviations}

IPT: Isoniazid preventive therapy

TB: Tuberculosis

\section{Declarations}

\section{Ethics approval and consent to participate:}

This study was approved by the Ethics Committee of the Hospital Nacional Dos de Mayo and the Ethics Committee of the Directorate of the Integrated Health Networks of South Lima (DIRIS Lima Sur). Written informed consent was obtained from caregivers for their participation in the survey and for the collection of data from the medical records of their children.

\section{Consent for publication:}

Not applicable

\section{Availability of data and materials:}

The datasets analyzed during the current study are available from the corresponding author on reasonable request. 


\section{Competing interests:}

The authors report no competing interests.

\section{Funding:}

This study was funded by the Dirección de Investigación y Creatividad Intelectual (Research and Intellectual Creativity Directorate) of the Universidad María Auxiliadora. CMY was supported by the Ronda Stryker and William Johnston Fund at Harvard Medical School.

\section{Authors' contributions:}

JZH, RZC, and MCR conceptualized the study. RZC, VEP, and JZH collected the data. CMY performed the analysis. JZH and CMY wrote the first draft of the manuscript. All other authors revised it critically and approved the submitted version.

\section{Acknowledgements:}

Not applicable

\section{References}

1. World Health Organization. Global Tuberculosis Report 2019. Geneva: World Health Organization; 2019. https://www.who.int/tb/publications/global_report/en/. Accessed 2020 June 05.

2. World Health Organization. WHO consolidated guidelines on tuberculosis: module 1: prevention: tuberculosis preventive treatment. Geneva: World Health Organization; 2020.

https://www.who.int/publications-detail-redirect/who-consolidated-guidelines-on-tuberculosismodule-1-prevention-tuberculosis-preventive-treatment. Accessed 2020 June 05.

3. 10.1016/S0966-842X(98)01216-5

Parrish NM, Dick JD, Bishai WR. Mechanisms of latency in Mycobacterium tuberculosis. Trends Microbiol.1998;6(3):107 - 12. Available from: https://doi.org/10.1016/S0966-842X(98)01216-5.

4. $10.1542 /$ peds.2014-2983

Starke JR, Byington CL, Maldonado YA, Barnett ED, Davies HD, Edwards KM, et al. Interferon-gamma release assays for diagnosis of tuberculosis infection and disease in children. Pediatrics. 2014; 134(6):e1763-73. Available from: https://doi.org/10.1542/peds.2014-2983. Accessed 2020 June 05.

5. Triasih R, Robertson C, Duke T, Graham SM. Risk of infection and disease with Mycobacterium tuberculosis among children identified through prospective community-based contact screening in Indonesia. Trop Med Int Health. 2015;20(6):737-43. doi.org/10.1111/tmi.12484. 
6. Van Zyl S, Marais BJ, Hesseling AC, Gie RP, Beyers N, Schaaf HS. Adherence to anti-tuberculosis chemoprophylaxis and treatment in children. Int J Tuberc Lung Dis. 2006;10(1):13-8.

7. Rekha B, Jagarajamma K, Chandrasekaran V, Swaminathan S, Wares F, Sivanandham R. Improving screening and chemoprophylaxis among child contacts in India's RNTCP: A pilot study. Int J Tuberc Lung Dis. 2013;17(2):163-8. DOI:10.5588 / ijtld.12.0415.

8. 10.1371/journal.pone.0154843

Mendonça AMC, Kritski AL, Land MGP, Sant'Anna CC. Abandonment of Treatment for Latent Tuberculosis Infection and Socioeconomic Factors in Children and Adolescents: Rio De Janeiro, Brazil. PLoS ONE. 2016;11(5):1-12. Available from: https://doi.org/10.1371/journal.pone.0154843. Accessed 2020 June 05.

9. Barbosa Silva AP, Trajman A, Hill P, Belo MTCT, Rabelo SG, Menzies D, Trajman A. Non-completion of latent tuberculous infection treatment among children in Rio de Janeiro State, Brazil. Int J Tuberc Lung Dis 1 de abril de 2016;20(4):479-86. DOl: 10.5588 / ijtld.15.0609.

10. Otero L, Battaglioli T, Ríos J, De la Torre Z, Trocones N, Ordoñez C, et al. Contact evaluation and isoniazid preventive therapy among close and household contacts of tuberculosis patients in Lima, Peru: an analysis of routine data. Trop Med Int Health TM IH. 2020 Mar 1; 25(3):346-56. Available from: http://search.ebscohost.com/login.aspx?direct=true\&db=cmedm\&AN=31758837\&site=edslive. Accessed 2020 June 05.

11. Chacón A, Alarcón E, López L. Factores asociados al cumplimiento de la terapia preventiva con isoniacida en niños en Quito, Ecuador (2014-2016 y 2018). Rev Panam Salud Pública. 2019;43(1):1-8. Available from: https://pubmed.ncbi.nlm.nih.gov/31892926. Accessed 2020 June 05.

12. Garie KT, Yassin MA, Cuevas LE. Lack of Adherence to Isoniazid Chemoprophylaxis in Children in Contact with Adults with Tuberculosis in Southern Ethiopia. Plos One. 2011;6(11):e26452. Available from: https://pubmed.ncbi.nlm.nih.gov/22069451. Accessed 2020 June 05.

13. 10.1371/journal.pone.0211934

Birungi FM, Graham SM, Uwimana J, Musabimana A, van Wyk B. Adherence to isoniazid preventive therapy among child contacts in Rwanda: A mixed-methods study. PLoS ONE. 2019;14(2):1-16. Available from: https://doi.org/10.1371/journal.pone.0211934. Accessed 2020 June 05.

14. Rutherford ME, Ruslami R, Maharani W, Yulita I, Lovell S, Van Crevel R, et al. Adherence to isoniazid preventive therapy in Indonesian children: A quantitative and qualitative investigation. BMC Res Notes. 2012;5:7.

15. World Health Organization. Adherence to long-term therapies Evidence for action. Geneva: World Health Organization; 2003. Available from:

https://apps.who.int/medicinedocs/pdf/s4883e/s4883e.pdf. Accessed 05 Jun 2020. Accessed 2020 June 05.

16. Suarez Cuba MA, Alcalá Espinoza M. APGAR Familiar: una herramienta para detectar disfución familiar. Rev Médica Paz. 2014;20(1):53 - 7. Available from: http://www.scielo.org.bo/scielo.php? 
script=sci_arttext\&pid=S1726-89582014000100010\&lng=en\&tlng=en. Accessed 2020 June 05.

17. Ministerio de Salud. Norma técnica de salud para la atención integral de las personas afectadas por tuberculosis http://www.tuberculosis.minsa.gob.pe/newtb/archivos/norma_tecnica.pdf. Accessed 05 Jun 2020. Accessed 2020 June 05.

18. Silva APB, Hill P, Belo MTCT, Rabelo SG, Menzies D, Trajman A. Non-completion of latent tuberculous infection treatment among children in Rio de Janeiro State, Brazil. Int J Tuberc Lung Dis Off J Int Union Tuberc Lung Dis. 2016;20(4):479-86.

19. Ambrona de Marcos V, Duque Jiménez T, Delgado Roche E, Aguilar Ariza R, Bravo Andrés N, Bach Foradada $\mathrm{P}$, et al. Compliance of latent tuberculosis infection treatment in a cohort of TB contacts. Rev Esp Salud Publica. 2018;92. Available from: http://search.ebscohost.com/login.aspx? direct=true\&db=edselc\&AN=edselc.2-52.0-85055900250\&site=eds-live. Accessed 2020 June 05.

20. Shieh FK, Snyder G, Horsburgh CR, Bernardo J, Murphy C, Saukkonen JJ. Predicting non-completion of treatment for latent tuberculous infection: a prospective survey. Am J Respir Crit Care Med. 2006;174(6):717-7. DOl:10.1164/rccm.200510-16670C.

21. $10.1371 /$ journal.pone.0182185

Szkwarko D, Hirsch-Moverman Y, Plessis LD, Preez KD, Carr C, Mandalakas AM. Child contact management in high tuberculosis burden countries: A mixed-methods systematic review. PLOS ONE. 2017;12(8):e0182185. Available from: https://doi.org/10.1371/journal.pone.0182185. Accessed 2020 June 05.

22. Diallo T, Adjobimey M, Ruslami R, Trajman A, Sow O, Obeng Baah J, et al. Safety and Side Effects of Rifampin versus Isoniazid in Children. N Engl J Med. 2018;379(5):454-63.

23. Yuen CM, Millones AK, Contreras CC, Lecca L, Becerra MC, Keshavjee S. Tuberculosis household accompaniment to improve the contact management cascade: A prospective cohort study. PLOS ONE. 2019;14(5):e0217104.

24. Silva AR da, Sousa Al, Sant'Anna CC. Barreiras no tratamento da infecção latente por tuberculose (ILTB) na criança: um estudo de caso / Obstáculos en el tratamiento de la infección latente por tuberculosis (ILTB) en el niño: un estudio de caso / Barriers in the treatment of latent tuberculosis infection (LTBI) in children: a case study. Esc Anna Nery. 2014;18(3):386 - 91. Available from: http://www.scielo.br/scielo.php?script=sci_arttext\&pid=S1414-. Accessed 2020 June 05.

25. Chang S-H, Eitzman SR, Nahid P, Finelli MLU. Factors associated with failure to complete isoniazid therapy for latent tuberculosis infection in children and adolescents. J Infect Public Health. 2014;7(2):145-5. DOI: 10.1016 / j.jiph.2013.11.001.

26. Venturini E, Tersigni C, Cordola C, de Martino M, Galli L. Latent Tuberculosis Treatment Compliance in Children: A 10-Year Experience. [Internet]. 2018 [citado 11 de febrero de 2020]. Available from: http://search.ebscohost.com/login.aspx?direct=true\&db=cmedm\&AN=29762390\&site=eds-live. Accessed 2020 June 05.

27. 10.1093/jpepsy/jsy044 
Psihogios AM, Fellmeth H, Schwartz LA, Barakat LP. Family Functioning and Medical Adherence Across Children and Adolescents With Chronic Health Conditions: A Meta-Analysis. J Pediatr Psychol. 1 de enero de 2019;44(1):84-97. Available from: https://doi.org/10.1093/jpepsy/jsy044. Accessed 2020 June 05.

28. Cedeño Ugalde MA, Figueroa Cañarte FM, ZambranoBarre JR, Romero Castro CV, AriasNazareno CV, Santos Andrade EA. Apoyo familiar en la adherencia al tratamiento de pacientes con tuberculosis. Dominio Las Cienc. 1 de diciembre de 2018;5(1):54-68. Available from: http://dominiodelasciencias.com/ojs/index.php/es/article/view/850. Accessed 2020 June 05. 